SB

389

. HT8

HOW TO MAKE
GRAPE CULTURE
P R OF I TA B L E
IN CALIFOR IA
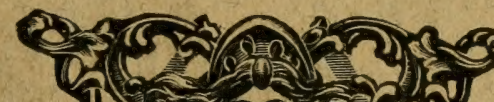

(1)

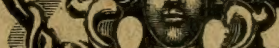

bou 101

Tisinases

(Sin)

(2)

$\operatorname{lis}_{5}$

WITH EXPLANATION

OF CALIFORNIA

Df $V$ I $N$ E O R ANAHEIM DISEASE

By H. HOOPS, Wrights, California 

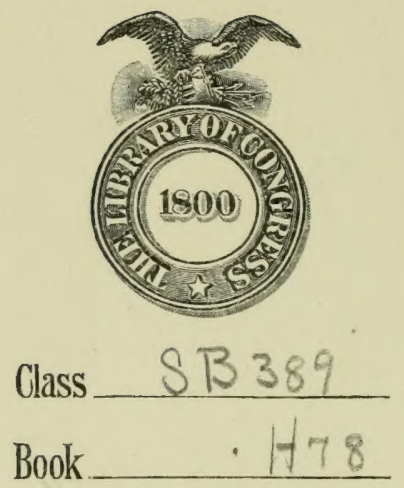

\section{Copyrightt $\mathrm{N}^{0}$.}

COPYRIGHT DEPOST: 


\section{HOW TO MAKE}

\section{GRAPE CULTURE PROFITABLE}

\section{CALIFORNIA}

WITH EXPLANATION OF CALIFORNIA VINE OR ANAHEIM DISEASE

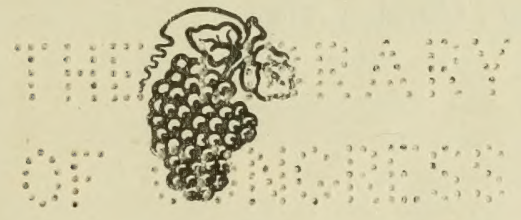

B Y

\section{H. HOOPS}

WRIGHTS, CAL. 


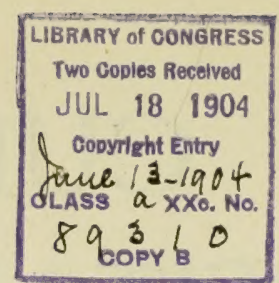

\section{PREFACE.}

In writing this booklet it is not my aim to give anything that can be found in other works of a similar nature or the current agricultural periodicals, but shall try to explain, as much as my poor ability as a scribe allows me, the ideas and methods which have proved valuable in my own viticultural practice.

Although in the choice and treatment of varieties of grapes my suggestions pertain principally to coast regions of northern California; I believe that viticulturists living in interior localities will be assisted by them in the improvement of their own practices and in the selection of better varieties adapted to their own local condi.tions.

In regard to my explanation of the California vine disease question, I shall let that part of the book speak for itself, and it would be untimely for me to make any further comments on it. I shall leave this to the intelligence and fairness of the California vine growers to decide whether I am right or not in my conclusions.

Wrights, Cal., March 1, 1904. H. HOOPS.

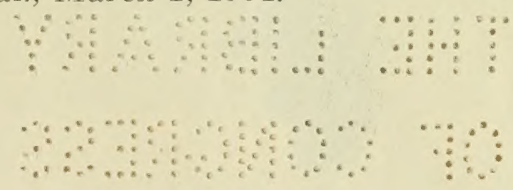




\section{California Vine or Anaheim Disease-Its Cause and Nature.}

This disease has been under my special observation for the last five years. It may have been in this vicinity longer than that, but if it was, I did not notice it. The varieties mostly affected are the Muscat of Alexandria, Black Ferrara and Cornichon, and these only in such places where the soil is rich the vines grew vigorously and bore heavy crops. Where, for certain reasons, they did not grow vigorous foliage or bear abundantly, whether the soil was poor or rich, they have remained healthy so far. This seemingly would prove the contention of some, that the heavy bearing of a vine is the cause of the trouble. But Viniferas produce heavily also in countries where the disease is unknown, besides vines have died with it that did not bear at all.

After observing the disease closely for the last four or five years, I believe, I do not make a mistake when I claim, that its prime cause is the great change in the moisture contents of our soils from wet in the spring to dry during the latter part of the summer; as it occurs in California on irrigated lands as well as unirrigated. If the soil was always as wet as in the spring or always as dry as during the latter part of the summer, no matter how smali the growth of the vines, there would not be this disease.

In order to prove this more clearly, I irrigated some Muscat and Black Ferrara vines heavily during the fore part of June two years ago, as well as last year, by soaking up the ground thoroughly around them. The vines were about 15 years old and sinod on ground which had never been cultivated except the first year or two during their existence. The soil they grew on is a rich, deep, clayey loam. As I left the trench unworked the water soon evaporated and the ground was as dry as ever. Some of the vines had an attack the first summer and the others this summer, while all the rest of the vines on the same uncultivated ground, which were not irrigated, are as healthy and thrifty as ever, in fact went through this last most trying of all dry seasons in this locality better than any of my vines on cultivated ground. This was because the ground was dry already when they started growth in the spring and the change from wet to dry, therefore not so great. I have made other observations and conducted other experiments to prove this cause as asserted, but it would lead off too far to explain them here.

I suppose the roots of most vines are similar to cuttings; if cuttings have been kept too wet and then are exposed to the air, they will dry out in a short time and be worthless; but if they have beeri kept in dry sand, they will endure exposure for a long time. Standing in a wet soil during the forepart of the vines' seasonal growth leaves the roots with less power to resist dryness later on.

I guarantee that vines cultivated and irrigated both, as laid down by myself in the chapter on preventive methods, will never be attacked. On the other hand I guarantee to produce the disease in a vineyard of a uniform clayey or loamy soil, where Viniferas on 
their own, California, Riparia or Rupestris roots are twelve or more years old, but where at present no disease exists, by causing the greatest possible difference through cultivation and irrigation methods between moisture contents of soil during May and June, so that the vine throws out immense foliage and sets a heavy crop, and moisture contents of soil during July and August, within three years from commencement of treatment. This would be easy work indeed, but I may be able to do the same thing with a five-year-old vineyard, at least in some localities.

The greater the difference in the moisture contents of a soil be. tween spring and fall, the greater the liability of the vines to attack, not considering the slight resistance which some varieties of Vinifera possess. Such is generally the case in all rich clayey or loamy soils, as these have the greatest capacity for holding moisture and at the same time offer the greatest facility for the complete escape of moisture through capillary attraction. The vine on such soils causes its own destruction by evaporating and depleting the soil moisture through its excessive foliage and crop. Like a good many, I have been under the impression that on rich ground the moisture supply never gave out. Digging down once during August and September in places where I knew the ground was heavily charged with moisture during spring and had been carefully cultivated and the vines made immense growth. I found the ground just as dry or drier than in the poorer places, where the growth was much smaller. The change from wet to dry was much greater on the rich than on the poor ground and therefore the vines suc. cumbed more quickly.

Different from countries with summer rains, a distinct difference must be made in California in regard to soils between the terms "rich" and "moist," and "poor" and "dry." A rich soil is gen. erally wet or moist in the spring and by careful cultivation remains moist if there is not much growing on it, but if any vines or trees with large top-growth are drawing from its moisture supply, it may become exceedingly dry. A poor soil is not necessarily dry during the latter part of the sum. mer, unless it is shallow or clayey at the same time. If it is loose, deep and mixed with gravel and small rocks, which form an impediment to the rising of the moisture to the surface, it generally remains much moister than richer soils. As vines do not grow so exuberantly on such soils, the moisture supply is not depleted. Very deep, coarse soils in valleys may become dry, as the moisture sinks away out of reach of the roots and what is left near the surface, is soon exhausted by the vines.

The trouble, of course, is greatly augmented by excessive bearing of a vine and by irregular moisture contents of a soil from year to year, very dry seasons following wet ones and vice versa. It is simply a collapse, paralysis of the vital energy of the vine, brought about as mentioned. It is not an infectious disease; no vine will take it from another. If the trouble was of such a nature, there would not be any vines left, even in northern California, at this time, as the disease has been found and identified already sixteen years ago in 
parts of Napa and Sonoma counties by Professors Viala and Seribner.

That in some localities whole vineyards have died in a short time, is because in the first place the cause and the augmenting factors mentioned, were very pronounced; in the second place the vines stood on a uniform soil, made uniform growth and therefore died off uniformly. On account of the richness and great uniformity of all alluvial soils the trouble has been greatest in valleys. Mountain soils are more "spotted," and for this reason the disease has appeared only in spots so far, wherever conditions were most favorable.

It has been called by some the vine-top disease, also in some of the earlier reports the statement is made, that the disease firs: appears at the end of the canes. This is wrong; tops and roots are - attacked simultaneously, although generally in a different degree. If the roots were sound, there would be a bushy growth of healthysuckers coming from its base. As it is, if these come at all, they only come sparingly and sickly from the beginning. True, the symptoms of the disease are first visible on the young foliage.

To ascertain this more clearly, I root-pruned during the winter several vines, which had made vigorous growth the preceding summer, but which had shown signs of attack in yellow spots appearing on their leaves, by digging a trench around them about three feet deep and four feet from their bases. As the soil was shallow but rich and the vines extended their roots horizontally in all directions twenty feet and more, the root-pruning was thorough. I also root-pruned some healthy vines in the same manner. Examining the roots of these vines the following summer I found the young root-growth on the healthy ones strong and sound, but on the attacked ones small and sickly, similar to the top-growth.

If we are anxious to give a name to the disease, I believe "Paralysis of the Grape Vine" is the most appropriate one. I shall point out a few similarities between human paralysis and the California vine disease: In both vital activity, which manifests itself in man principally in voluntary motion, and in the grape vine in the growth of new wood, is impaired, although without any outward sign on the main body. In both the young are less subject to an attack than the old. Like a human the vine sometimes is affected on one side only, while the other side remains healthy at least for some time. A predisposition to attack is increased in man by rich living, so vines on rich ground are more susceptible to the disease than vines on poor ground. In human paralysis there are different degrees of attack, so vines are attacked differently, some more severely than others.

It is a curious fact that cuttings taken from only slightly affected vines will grow fairly well as long as the vines are young, the soil moisture is not exhausted and so the cause of the disease does not exist, but as soon as this appears again the vine has another attack during the latter part of the summer and then fails to make proper growth the following spring.

In grafting an old Muscat vine three years ago, which had suf- 
fered a stroke on one side, to Cornichon, a much more resistant variety with me, I inserted a scion into the healthy portion of the stock. The graft making but small growth the following two years, the vine recovered. If this was a disease, permeating the vine from a small beginning, recovery would have been impossible, considering its fatal character otherwise.

The gist of the whole matter is, the Viniferas and several American species are not exactly adapted to California soil conditions, or rather moisture conditions in the soil as they generally exist in cultivated ground. They cannot adapt themselves at first to an excess of moisture and bountiful supply of food and within a short time afterwards to great dryness and scantiness of nourishment. Thc vine not being a rational and economical being, during the forepart of summer throws out a much stronger foliage and sets a much heavier crop than it can support properly without injury to its vitality, although at the time without any apparent distress. This exceedingly free and excessive growth of the Viniferas, and still more so of Riparia and Rupestris, during the early summer constitutes a second cause to the disease. We cannot lessen the moisture supply of the soil during the forepart of the vine's growth very well, except by quitting irrigation at this time where this is practiced, but we can avert the weakening of the vine during the latter part of the summer through preventive methods. These will be necessary, as the susceptibility of the Viniferas to attack by the disease increases from year to year, so that in the future no locality will be exempt from its ravages without their employment.

In conformity with my views the Lenoir has shown itself a resistant. I shall state here, that whenever the word "resistant" is used in this treatise, it means resistant to California vine disease, unless otherwise stated. The Lenoir as is well known is adapted to wet, heavy soils and also to dry ones, if these are clayey. It is a hybrid of Vitis cinerea, adapted to heavy, wet soils, and a Vinifera and Astivalis variety, best adapted to drier conditions.

The Champini also has outlived almost any other vine in the Santa Clara Valley. It is a hybrid of V. candicans with Rupestris, The former is adapted both to very wet and dry conditions. Although the Champinis are generally recommended for "dry" soils only, they certainly must also have some resistance against excess of moisture, as they take considerablly after Candicans. For this reason vines like Riparia, Rupestris and Vinifera, not possessing the wide range of adaptation to the great changes from wet to dry, as the two vines mentioned, have succumbed.

It seems that such resistants can be obtained only by hybridization and especially by hybridizing species, adapted to wet, with some adapted to drier conditions. Certain it is, that by hybridizing varieties of different species, adapted to different climatic and soil conditions, vines can be produced, possessing a much greater power of adaptability than either one of the parents. But it is very likely, that certain species, as the Cinerea, Cordifolia, Berlandieri and especially the Candicans, have a great flexibility of adaptation in themselves. Vines found wild on soils of a close or compact tex- 
ture in countries, where drouths are not infrequent, must possess this characteristic, while vines found wild on loose sandy or gravelly soils, where the extremes of wet and dry do not occur, are devoid of the adaptability to such conditions. As we cannot use the vines mentioned, on account of non-rooting of their cuttings, we shall have to take recourse to their hybrids with Vinifera, Riparia and others, which have not this fault.

There are two points in the general characteristics of Rupestris St. George, which speak against its success in California viticulture. The first and most important is, that it does not thrive in dry shallow soils in France, although it is drouth-enduring in "dry" (?), deep soils on account of its deep-rooting. This shows that its roots in themselves are not resistant to dryness. The second point is that in wet soils it is affected with root rot. We can see by this that it has only a narrow adaptation. It is a hybrid of $\mathrm{V}$. Monticola and Rupestris or, as claimed by some, of the former and Riparia. It partakes of the characteristics of the pure Rupestris varieties, but has the advantage over these in its thicker, more penetrating and vertical roots, which enable it to get a quicker start in most any soils, but especially compact ones.

The Riparia and Rupestris varieties should as a rule not be used except where irrigation is possible, and even there I believe other varieties will prove more valuable. I doubt that the Rupestris as grafting stocks are more resistant against extreme dryness than the Riparias; I even doubt that they are as hardy against moisture changes in the soil as the latter; only on account of their habit of sending down their roots deeply into the substrata, where they generally find plenty of moisture in all countries with summer rains, they are more drouth-enduring. But in California conditions are cifferent. As has been stated, in all soils of a compact nature, including gravelly clays and loams, especially in valleys of an alluvial formation, the diffusion of moisture through capillary attraction is so even and uniform, that if these become dry two or three feet below the surface, they are also dry fifteen or twenty feet further down, providing there is no moisture near arising from ground water. A vine sending down its roots deeply into such soils therefore has but little better show that a more shallow-rooting one. Of course I do not want to be understood, that deep, penetrating roots of a stock, whether these are laterals from horizontal main roots as in the case of the Lenoir, or are vertical main roots as those of the Champini, are not preferable in California in anv soil, as we cannot always tell what is hidden under the surface. On the other hand mountain soils, especially the deep, loose, gravelly ones, which are generally underlaid by an impenetrable substratum, which does not allow the seepage coming down the hillside to escape out of reach of the roots, give most any kind of a vine a better chance. Compact soils in mountains are more similar to valley conditions.

While the Riparias require a rich, moist soil, the Rupestris are adapted to poor, moist gravelly or sandy soils. They cannot endure continued dry or wet conditions, nor great changes from wet to dry. The Rupestris St. George is similar to these latter, but as has been 
stated, on account of its more penetrating roots takes a quicker start and grows more vigorously. But any vine, which makes vigorous top-growth, will soon exhaust the soil moisture in California, and then if it has not an inherent resistance to dryness, will succumb. My experience with the Rupestris St. George is, that it grows exceedingly well while young, but as soon as it receives a Vinifera top, attains full size and exhausts the soil moisture, it begins to show signs of distress. It may do fairly well on deep, loose, poor, gravelly hillsides in localities with ample rainfall and careful cultivation, but even on such soils the Champini will grow and pay much better.

I shall say here that the same cause may prevent the thrifty growth of a vine or effect its death in some other manner; this would be more the case on the poorer soils. For this reason also Viniferas, grafted on Riparia or Rupestris, contrary to French experience, do not bear so well or produce as large grapes in California, as they do on their own roots. The fruit and leaves of a vine sumburning badly, can also be traced back to this. It is not caused entirely by the direct rays of the sun, as is supposed by most, but indirectly and principally by the dryness of the soil. Whenever. some of the roots become distressed, it affects those grapes and leaves, which are fed by them. The sumburning occurs on rich as well as on dry ground for reasons, which can easily be seen from explanations in other parts of this treatise. It may easily be deducted from the above that not much can be expected from the Riparia-Rupestris hybrids.

One of the principal differences in the characteristics of plants of cold and those of tropical and semi-tropical countries is the greater or less amount of heat there is required to cause evaporation of moisture through their foliage and so vital activity. Tropical plants transplanted into cold countries would die for want of proper exhalation of moisture and sap circulation, and cold climate plants transplanted into hot countries would die on account of a too rapid evaporation of moisture through their leaves, but these latte: would last much longer under such conditions, if the soil contains plenty of moisture, than if it is deficient in this. We see by this that adaptation to certain climatic and soil conditions rests not only in the roots of a plant but also in its foliage. For this reason topgrafting resistants on non-resistants has been quite effective in saving Viniferas for a number of years; for the same reason, grafting non-resistants on resistants has not been a complete success, at least not in certain localities. But as some very fair results have been obtained with grafting stocks like Lenoir, Champini and others without any other precautionary measures, a much better showing can certainly be made in the future, considering our better knowledge of the matter. 


\section{CHAPTER II.}

\section{Preventive Methods of California Vine Diseases. 1. Method. Selection of Proper Resistant Grafting-Stocks.}

There are four requirements with which good resistant stocks should comply: 1. Resistance to California vine disease or greatest possible range of adaptation to the changes from wet to dry in the soil; 2. Resistance to Phylloxera; 3. Adaptation to other climatic and soil conditions; 4. Affinity and good general behavior after grafting to Viniferas.

In order to overcome the weakness of the Vinifera top and as any slight injury to the roots of a vine or tree may cause overbearing, an augmenting factor to the disease, it is plain, that only grafting stocks possessing the highest resistance against the Phylloxera as well as the greatest flexibility of adaptation both to wet and dry conditions of the soil, are perfectly safe. A resistance-coefficient of 16 is generally considered high enough for any soil, as it makes the vine safe against any injury to its roots by the Phylloxera. This does not say that a higher one is not preferable, provicling the othe! qualities of the stock in question are as good. I have been under the impression for some time, that vines with thick fleshy roots are the best for California conditions. Of two vines, having the same adaptability, the one with the thickest roots will be the most dryness-enduring. For this reason the Solonis, which has small roots but a great adaptation to short changes from wet to dry and vice versa as is attested to by French experience and that of Mr. T. V. Mun son, does not last at all during our long, dry summers.

It does not matter materially, whether the main roots extend themselves horizontally and the laterals run down deeply, or the main roots approach a vertical direction. I believe, for rich, level and irrigated lands I should prefer the former, as I think they will give better results, and for loose gravelly soils the latter. In such soils the moisture cannot rise to the surface by capillary attractions, but settles down by gravity; the usefulness of a vine with very deep vertical main roots is therefore apparent

New vines intended for stocks can be tested in the following manner: On a piece of level, clayey ground, either shallow or of an even texture to a great depth, some of the vines should be planted along with some Lenoir, Vinifera- and Riparia-Berlandieri for conparison. They should be either rooted cutting-grafts, or if ungrafted should receive a Vinifera top as soon as large enough for grafting, as testing stocks with their own tops would be of no importance, because they act quite differently after being grafted. In order to accelerate the testing it is best to plant the vines rather close, about six feet each way. The plot should be well cultivated the first two years in order to enable the vines to get a quick start. The third year the ground should also be well cultivated up to the last rain: after that it should not be stirred any more, in order to let a crust form on the surface. During June it should be irrigated about once a week, to soak it up well with water and the irrigating furrows left 
unstirred, to facilitate the escape of moisture after irrigation is discontinued about the last of June. No matter how the work is done, it should be performed so, that the ground is excessively wet during June and excessively dry during July and August. This last point should be ascertained, as the young vines would use up but very little moisture. The fourth and fifth year the experiment of the third year should be repeated. After the fifth or sixth year some oi the vines should be taken up to see if any dead roots are present.

For vines intended for loose, gravelly soils on hillsides in the coast region such a severe test as the above would not be necessary. A piece of ground of gravelly clay could be selected for the testing plot and then treated in a similar manner, but without irrigation. The test as directed above is according to the climatic conditions of my own locality, the Santa Cruz Mountains; the same conducteri in some other places would need modifications. The vines should not suffer so much during July, August and September, as to be entirely stunted and so be unable to make vigorous growth the following spring. A vine injured so much as not to do this, as is the case when it is badly damaged by the Phylloxera, is not attacked by the disease. To make sure, that a stock entirely overcomes the weakness of its Vinifera-top and makes it perfectly immune from attack by the disease, would take a long time, i. e. if healthy scions arc taken for grafting. If such are not taken then the test would be inadequate. All we can do is to find a hardy root, which corrects as much as possible the faulty tendencies of its Vinifera top, which are excessive spring-growth and lagging activity during the latter part of summer. In what degree this is accomplished can be seen in the course of five or six years, if the above directions are followed. Most anybody with an observing eye will be able to tell in a few years, which will do and which will not. Those, which make the most vigorous growth from the beginning are not necessarily the best, in fact stocks which cause their Vinifera tops to make earlier and more excessive spring-growth like Riparia and Rupestris do. will also increase their susceptibility to the disease. The ideal stock should cause its graft to make later and less vigorous growth during spring and the leaves of the latter should not lose their healthy, glossy appearance during July and August, nor the even ripening of its fruit come to a standstill. The Lenoir and the Champini come very near having such an effect on their Vinifera top. A perfect development of the fruit is the best indicator of the hardiness of the root of the vine or its adaptation to existing soil conditions.

A third and probably the quickest and most efficacious test, if properly and carefully conducted, could be made by grafting on the resistant stocks cuttings taken out of a vineyard in which a good many vines have been killed off by the disease. These cuttings should be taken from the remaining, apparently healthy vines preferably of varieties which succumb very slowly and gradually, but surely, like the Muscat of Alexandria. They should be cut up in scion lengths, then well mixed and grafted on the stocks to be tried. Some vines like Lenoir, Champini and others, whose hardiness is known, should be planted in the same plot for comparison. Such 
grafts generally, if the ground is worked as directed for the firsi mentioned test, will show the disease in a few years, no matter how hardy the stocks, but it can easily be ascertained by this method, what stock has the greatest beneficial influence on its Vinifera top.

I am inclined to think that it is best in California to plant hardy resistants, which are free growers, ungrafted in the field and let them go without grafting for three or four years and in localities, where the disease has been very destructive or if Viniferas are wanted, which are very susceptible to the disease, even longer. In postponing the grafting, the vines are not weakened with a Vinifera top, while very young, as the latter is apt to weaken most any stock, which will be explained later. It is possible that certain hardy resistants which are slow growers, are induced to quicker growth, if they receive a Vinifera top while very young, as the more quickly and freely growing Riparia and Rupestris stocks have this same effect on their grafts. In such cases it may be advantageous if a quicker growth is desired, to make cutting-grafts or graft the vines in the field while they are young. .

\section{Species of Vitis, Valuable for Hybridizing in the Creation of New Grafting-Stocks.}

V. candicans or Mustang grape. This is considered the hardiest of any American species and occurs according to T. V. Munson, in lower as well as upper bottoms of upland ravines on the "black waxy lands." Such soils are exceedingly wet while the rains last, but become during a drouth exceedingly dry, much drier than the more elevated, loose, gravelly soils, generally called dry. In fact two of its hybrids. Champini and Elvicand (Cand. Riparia Labrusca), have outlived any other vines, used as grafting stocks on Mr. William Pfeffer's place in the Santa Clara Valley.

$\mathrm{V}$. cinerea. This vine has thick, fleshy roots and occurs wild on rich heavy soils, although also on rich sandy soils. From it its jrogeny, the Lenoir, has undoubtedly inherited the greater portion of its wide range of adaptation. I should like to ask those, who claim the Lenoir to be a pure Vinifera, how they explain its great resemblence to the Cinerea in leaf and root; also, where its resistance to Phylloxera comes from. It would be the only Vinifera possessing this resistance.

V. cordifolia occurs on "the lower and higher bottoms of upland ravines." It has produced vines having the largest trunks of any American species and has very thick, penetrating, highly Phylloxera-resisting roots. The hybrids Riparia-Cordifolia-Rupestris 1068 and Solonis-Cordifolia-Rupestris 2024 may have some value for California, but no attention must be paid to French experimenters' recommendations of vines for clays. The fact is that even for our gravelly and sandy unirrigated lands we can use with safety only vines which have stood the test on clays in countries with summer rains and only very few kinds of such. I don't think the two hybrids mentioned are as well adapted to California clays as the 
Lenoir is and can fill its place; still they may have great value for soils which have been considered well suited for Riparia heretofore. Most any vine, which thrives in clays, will do well also in gravelly or sandy soils of rich or medium quality.

V. Berlandieri. This species occurs along the top of limestone ridges as well as on creek bottoms of western Texas and adjoining territories, but it is also found on compact soils. As this is in a very try region, its scope of adaptation probably approaches more extreme dry than moist conditions. It is probably more dryness-enduring than any other species of Vitis. The Riparia-Berlandieris are recommended to us by French experimenters as possessing the very qualities which will prove so valuable in California. The Vinifera- and Rupestris-Berlandieris will very likely also have very great value, especially for coarse gravelly soils or dry clayey ridges and slopes in mountains, which never hold a great excess of moisture. The above named four species have a great affinity in grafting to the Viniferas, which is very important.

$V$. riparia. I am of the opinion that the roots of vines of this species have a fairly good adaptability to moisture changes provided the soil does not become too dry, but on account of their fineness, shallowness and lack of penetrating power, the Riparia as grafting stock has, as a rule, not been a success on unirrigated lands in California. Considering its value as a grafting stock in other respects, Riparia hylorids therefore without the faults of the pure varieties and all their good qualities should prove a success.

V. rupestris. This species has little adaptability; the pure varieties therefore have no value for California. Hybrids possessing their adaptability to poor soils and their deep, downward roots. but stronger and hardier, would have usefulness for poor gravelly soils. Very much misleading is in French writings on viticultural topics the expression "dry soils," by which generally coarse gravelly soils are meant. True, deep gravelly soils, which are the only ones that have been found to be well adapted to Rupestris in France, are not excessively wet during a rainy spell, but neither are they as dry in their lower depths at the end of a drouth as the richer close-textured soils. The Rupestris occurs wild in the gravelly and rocky beds of "dry" runs and creeks, which contain no water visible after springtime, but in a good many cases this has simply sunk out of sight. Moisture arising from such water, with occasional rains produce ideal conditions for this species.

$\mathrm{V}$. californica. This, our own native vine, whose great value in this respect has been unwisely overlooked in late years. Its fault of lack of proper resistance against Phylloxera and of sufficient hardiness should be very small trouble to correct by proper hybridization with any of the four species ahead in this list. No vine of purely American origin is superior to it in adaptation to our climatic conditions and in easy rooting from cuttings. Riparias and Rupestris, especially the latter, which is apt to give a treacherous character sen to a hybrid, conld be dispensed with entirely, as the Californica will do better than either of the two in most any soil. poor or rich. 
$\mathrm{V}$. vinifera.This last, but not least, on account of its large and spreading roots and great adaptation to different soils; it also supplies a greater affinity and homogeneousness to the stock with its Vinifera top. The stronger the root system and the closer the relation between stock and graft, the better are the chances of success. A hybrid like Aramon Rupestris No. II may give fairly good results, where proper irrigation can be practiced, but I believe, hardier stocks than this or Riparia will prove more profitable, as less water will be required and a better quality of fruit obtained.

It is always safest to employ several different resistant stocks for the same Vinifera variety with special reference, of course, to their like or dislike of existing soil conditions and to their affinity to intended grafts, as our experience in this line is too limited to tell to a certainty, what stock will prove the most successful, and so serious losses are avoided and in course of time a good deal of practical knowledge is gained. All we can do at present is giving the Viniferas a root, which is hardy against moisture changes in the soil and resistant to Phylloxera. What stock will exercise the greatest influence on the grafts in regard to good behavior and longevity of vine, only time will tell. With proper grafting-stocks and selection of healthy cuttings for scions, as will be explained immediately below this, better results should be obtained than have been with the first importations from Europe, not considering other preventive measures, which we can take. The four species Candicans, Cineria, Cordifolia and Berlandieri attain large size and have great vigor in their native home, but make only a sluggish growth under California climatic conditions. Their value is in hybridization with species which grow too freely during the forepart of summer. Those hybrids which take more after the named species in their habit of growth, will very likely be valuable for hot interior locations or places, where the California vine disease has been very destructive, while hybrids, taking more after Vinifera, Riparia, etc., will have the greatest value for cool, moist coast mountain regions, or where vines like Petite Sirah, Beclan and Cabernet are intended for grafts and have too little vigor on their own roots.

\section{Method. Selection of Healthy Cuttings for Scions.}

This is probably the most serious part of the problem, as it will be difficult in a good many parts of California to get such. The disease does not come as suddenly with a good many varieties as is generally supposed. The Muscat of Alexandria, for instance. will bear heavy crops with me for years, after having sustained its first attack. Others like Black Ferrara succumb more quickly. Yellow or brown spots on the leaves during the latter part of the summer are generally a sure symptom that the vine has suffered an attack. With some varieties the leaves curl up and the spots are very small. The fruit and the wood fails to mature and develop pronerly, the berries being sour and of small size. The following spring, according to the severity of the attack, the vine makes only a small growth or none at all. If the attack was very light, the 


\section{I4 How to Make Grape Culture Profitable in California}

growth may reach half dimensions, but in a year or two generally another attack follows, which kills the vine. A predisposition manifests itself in excessive crops, less in loss of vigor. As has been previously stated, cuttings taken from only slightly affected vines will grow fairly well for a few years,but soon succumb The Viniferas growing for a number of years under favorable soil conditions in California, a strong predisposition to the disease is created or augmented in them, long before they are actually attacked. Vines propagated from cuttings, taken from such apparently healthy vines, will make satisfactory growth for several years, but if conditions for the development of the disease become more favorable again, will succumb much more quickly than the mother vines, from which they originated. It is, therefore, very unsafe, to take cuttings out of a vineyard, in which the disease has appeared to any extent, and especially unsafe if such a vineyard is old and located on alluvial soil in a valley, where the disease has been very virrulent in other parts of it. It is very probable that the reason why in former years the disease has been less conspicuous, is because the first vines were propagated from perfectly sound cuttings, imported from Europe or which came from young perfectly healthy vines. A similar degeneration is met with in annual plants, as some kinds of potatoes, wheat, etc., which, when first introduced into a new locality, do exceedingly well, but after their culture for 3 or 4 years degenerate and fail to give satisfactory 1eturns. Propagation through cuttings is simply a prolongation of the life of the old vine and young vines thus started commence life with all the weakness and infirmities of the old mother vines.

It is a good plan to have a plot of vines simply for the purpose of obtaining cuttings for new plantations. These vines should be carefully irrigated according to directions given below. Care should be taken that only sound vines are planted in such plots; they should be grafted on stocks which are known to be hardy. Where cuttings are taken from a field it is safest to take them from young vines from three to six years old. Cuttings taken from vines on poor gravelly hillsides in cool localities with ample rainfall are better than if taken from vines on rich ground of any description or any locality. Instead of grafting resistants on old worthless Viniferas for the procuring of strong cuttings, as the prevailing custom is, they should be grafted only on young vigorous vines, or still better, if such mother vines stand on their own roots or on some other hardy stocks.

In localities where the disease has been very destructive it is probably best to grow only such Viniferas, which in the past have shown the greatest resistance to the trouble. These are according to my experience those varieties which start growth late in the spring, mature their fruit early, do not overbear nor make excessive vondgrowth, as Petite Sirah, Beclan, Franken Reisling, Cabernet and others. Of course there are vines like Tokay, Verdel, Gren:che and Carignan, that have shown a greater resistance, if standing on a favorable soil than smaller growers and smaller bearers. probably on account of their stronger and more penetrating roots. 
But if the root given them is not as strong as their own, they may succumb more quickly or at least will not prove so profitable. It is rather difficult to tell at the present time, what Vinifera variety is the most resistant to the disease, as this would depend on the length of time a variety has been cultivated in California, whether the first imported cuttings were propagated on their own roots or grafted on some old Vinifera vines, on what soil and in what locality the first vines, which furnished most of the cuttings for late: plantings, were grown, etc.

\section{Method. Proper Preparation of the Soil Before Planting.}

Before vines are planted the ground should be turned over deeply, no matter how rich the soil. To run a subsoiler in the furrow is an improvement to the old method of simply plowing the ground; but even this can be greatly improved by following the first plow up with another plow in the same furrow instead of the subsoiler and throwing the bottom soil up on top. The humus of which there is a considerable amount left in most surface soils, should be turned down as deeply as possible, in order to prevent combustion of its organic matter, so disastrous in its effects during our long dry summers, and the purely mineral ingredients of the subsoil turned up to the surface for exposure to the air, light and rains, to dissolve their plant foods. While doing this work, if the topsoil is devoid of humus, do not forget to put abundant organic matter in the form of green or stable manure, straw, etc., in the bottom of the furrow and remember that this is the only chance you have to cause any material good with such things in a vineyard growing under California conditions. Young vines planted on such ground will extend their roots deeply, as they find nitrogen of which they are in great need and the best of other ready plant foods at a depth that will not easily get dry. If these foods are near the surface, the vines will either have to do without them or else their main roots will be very shallow and more exposed to moisture changes. Such described work puts the physical condition of a soil at its best, which is according to the experience of the best cultivators of the soil the most important.

The value of humus consists further not only in the fact that it is the sole source of nitrogen in the soil, but also in the generation of carbonic acid, so important in creating new and different combinations with mineral bases for plant foods directly and inclirectly, which would otherwise remain unavailable on account of their insolubility. This work as described has really but little to do with the point in question, but $I$ inserted it to make the following better understood.

\section{Method. Proper Cultivation.}

With the exception of the first year, during which they should receive good care in order to keep them alive, young vines should have only the minimum moisture allowance, absolutely necessary to keep them thrifty. How much this is cannot be given in a certain rule, as it would 
depend on the different soil and climatic conditions of different localities. It may be said that excessive moisture during sprins, should be avoidecl. Ifter the late rains in the spring the ground should be allowed to dry off well first before it is gone over with the cultivator or harrow, and then of course it should be worked thoroughly. Excessive soil moisture produces shallow and tender roots and soft top-growth, scantiness of moisture makes deep, hardy roots and tough top-growth. How well the moisture contents of a soil in (alifornia can be regulated by more or less creltivation is not as well understood as it should be. Even the Riparia can be hardened and made deep-rooting by such treatment.

Br the time the rines are seven rears old, ther will bo well acquainted with all the vicissitudes of California soil conditions. After that the moisture allowance should be increased gradually from year to year, as their larger growth demands it. It is abnut as harmful to the health of the rines to hold excessive moisture ir. a vineyard that previously has been neglected for one or more vears, as it is to neglect a vineyard that has had good care before. The more minform the moisture supply is one year after anothe?, the better it will be for the welfare of the vines. Very much mis.calculated is also the practice of some who raise nursery stock in a wet place with stagnant water near the surface. Such vines, especially if they are intended to go on dry ground, are worthless.

\section{Method. Summer Pruning.}

In order to prevent unnecessary woodgrowth and in consequence exhatistion of soil moisture, it is well to deprive the vine when it has attained an age of 6 or $\tilde{\sigma}$ years, of some of its foliage and stop its extending itself to its fullest capacity. In doing this I top those canes, that come down to the ground and trail along for some distance or which catch the neighboring vines, by cutting them off where they touch the rrouncl. This should be done before the canes become woody, about two weeks before the vine gets its full growth, generally with me about the first or second week in July. The rines will quit growing then, but if done too early it will have no effect, as they will throw out a lot of laterals and keep on growing. I know it is generally advised against such work, but I believe it is much better to check the vigor of a vine growing under California climatic and soil conditions somewhat than to have it collapse later on account of too much ambition. If not too many canes are topped or the work is done too late, I fail to see that it postpones the maturing of the fruit any. Where simple pinching of the terminal buds has the desired effect, as may be done with the smaller growers, then this is certainly preferable.

In order to do this work effectively the winter-pruning should be close and short. All suckers as well as some of the smalle: fruit-canes should be removed while they are small and can easily he rublecl off. It is best to go over a vinevard several times during the summer to do this and never should a large lot of strong suck- 
ers be removed at one time, as this would check the growth of the vine too much.

\section{Method. Thinning Out Old Vineyards and Root-Pruning.}

After the vines get about 15 years old and have quit extending themselves, or as soon as, or still better, before the first signs of the disease appear, I believe it best to thin out some of them, especially if they have been planted too close, as trees and vines generally are in California. This will give the remaining ones more moisture during the latter part of summer and make the difference between spring and fall moisture contents of soil less. These should be root-pruned during the winter about half-ways between the rows, which can easily be accomplished by horse-power with an implement, which could be devised for this purpose. On rich ground, the only kind on which it would be necessary, the mair roots of Viniferas and of a good many American species are shailow, generally from 6 to 12 inches below the depth the plowing has been done.

It is best to plant vines at a greater distance than they generally are. From 10 to 12 feet each way for valleys and from 9 to 10 feet for mountains is not too far. The distance should vary according to the richness of the soil, the richer and compacter this is the greater the distance. It does not matter much, whether the triangular or the square form is used; the number of vines to the acre will tell, whether there are too many or not. On very rich sandy or clayey loams in cool, moist localities, vines, which ripen theit fruit late, should not have quite the maximum distance, as this would retard the maturity of the fruit. As soon as such plantings are about 10 or 12 years old root-pruning should be practiced oc. casionally. As this has a dwarfing effect on vines or trees and decreases their vigor, its usefulness will be seen. Smaller vines and more space to hold reserve moisture for their proper maintenance is the object desired. If root-pruning is omitted, the vines will in course of time occupy the whole of the ground and make conditions as bad as ever. There are single vines in the world that occupy from one-half to one acre of ground. On poor gravelly soils where vines make but small growth, root-pruning is not necessary, as the vines have not enough vigor to extend their roots through the whole of the ground allotted to them, if planted far enough apart in the first place. No apprehension need be felt that they will not produce as heavy crops per acre as with closer planting. These will be just as large if not larger and a better quality produced. Although this will not come quite as soon, vineyardists will be amply reimbursed in the saving of labor and other expenses.

\section{Method. Grafting Over of Old Vines.}

Grafting over a whole block, or still better, a whole tract of vines, especially to more resistant Viniferas, is sufficient to post. pone the disease for several years, because for the first time, since attaining full growth, as the grafts start later and their growth is generally smaller, they have plenty of moisture during the latter 
part of summer. It is needless to say that the vines at grafting must be perfectly healthy.

Cutting down vines about an inch below the surface during winter also has a salutary effect. It may be better in California to do this towards spring, as the bleeding of the rines keeps back the growth till the excess of moisture has disappeared from the soil. This work should also be done in large tracts, as the moisture can be held more uniformly in the ground than if done in small blocks. It may also be that late pruning has a beneficial effect in this re. spect as it decreases the vigor of the vines somewhat.

\section{Method. Irrigation.}

This is probably the best preventive of any, if properly applied, but as it is generally practiced, i. e., filling up the ground with water in the spring, when it is too wet already, it is apt to make matters worse. Vines should not be irrigated, barring exceptional cases irom this statement, till about two weeks after the bloom. As irrigation during the summer creates shallow root-growth, this must be kept alive and healthy by a repetition of the practice, at least on heavy soils in some localities. Shallow root-growth can be prevented by plowing deep furrows to let the water down into the subsoil and so avoid moistening of the surface. Care shoula? be taken not to cut any of the main roots during the summer, as this would be apt to weaken the vine. It is self-evident that the furrows should be well filled up with loose, dry soil, after the ground is dry enough to do this properly. The water should always be applied in the same places. Young vines should not be irrigated, unless it is impossible, as may be the case in some interior localities, to keep them in healthy growing condition without it. In such cases it should be done early and not late.

The cause of the trouble may also be explained thus: The climatic and soil conditions of California being both very favorable during the forepart of the season, cause the vine to make excessive and soft growth in root and top; while the climatic conditions remain the same, the soil condition becomes very adverse later on. So a good way to strengthen vines again, which are weak already in this respect, would be to hold only a fair amount of moisture in the soil with spring cultivation and then irrigate heavily and frequently later in the season, where this can be done. For reasons obvious from the above young vines are seldom attacked, even if the cuttings used for their propagation were taken from vines, in which a predisposition to the disease was already strongly developed, be. cause they have plenty of moisture during the latter part of the season, as they do not make sufficient growth to exhaust the moisturc supply.

All these preventive methods are given with regard to Viniferas on their own roots. Whether these, excepting proper irrigatirm, would be of much avail for vines grafted on Rupestris, which has a much weaker adaptation in this respect than the Vinifera root has, I cannot tell.

Resume: In order to prevent the disease, be very careful in 
the selection of healthy grafting wood, decrease the excessive vigor of vine through choice of proper stocks, by summer-top and winter-root pruning; make it drouth-enduring, by giving it a hardier, more penetrating root and by diminishing its foliage somewhat, where this is excessive. It is possible that in course of time grafting-stocks will be found, which will make any other preventive method, excepting the selection of healthy scions, unnecessary. Where plenty of water is available, proper irrigation alone is sufficient to prevent the disease.

All preventive methods should be commenced in time. No diseased vine can be cured permanently; even a vine, which has developed a strong predisposition to the disease is difficult to save, unless a copious water supply for irrigation is at hand.

\section{Method. Spraying the Vines.}

In places where the conditions for the development of the disease are known to be very favorable and the two first mentioned preventive measures have been neglected, or in order to save vines which are very susceptible to the disease and show signs of weakening, another preventive may be employed or rather experimented with, viz: Spraying the vines with some liquid, preferably of a whitish color, which covering part of the leaves would prevent excessive evaporation of moisture and sap. In an experimental way I have found spraying with the Bordeaux mixture right after topping of the vines quite effective in this regard, but a cheaper spray may be just as beneficial. Some wild plants and shrubs with shiny. glossy leaves, which in spite of shallow roots and large tops or standing on solid beds of clay, are exceedingly drouth-enduring, have come to my notice. This glossy appearance of the leaves, which is most intense, the hotter the sun is, is undoubtedly causeci by the exudation of a gummy matter covering the leaves and preventing a too rapid escape of moisture. The upper surface of the leaves of Lenoir, Champini, Berlandieri and others presents a similar appearance. Some species and varieties of Vitis, which are known to be very hardy, but which do not possess glossy leaves, undoubtedly have a drouth-resistant power in their foliage of some other character. It is also possible that with some vines such hardiness rests altogether in the peculiar structure of thei: leaves and none in their roots, but the success that has been ob. ta.ned with Lenoir and Champini, points in the direction, where to get our grafting stocks.

As an example of the anomaly, just mentioned, I may nane the Rupestris St. George, which seems to be much hardier before than after grafting. Its strength lies in its top and its weakness in its roots in spite of their great penetrating power. The weakness of the Viniferas is in their foliage and their strength in their roots at least in this respect. If we could create a Phylloxera-resistant stock with the large and spreading roots of a Tokay, for instance. but much hardier, we should have a valuable grafting stock. For this reason the Lenoir, which has hardy thick roots and is a Vinifera-American hybrid, comes nearer being as ideal a grafting stock, 
at least for rich soils, as anything we have at present, if it only had a higher resistance against the Phylloxera. It is not adapted to poor gravelly soils as the Champini is. On account of its Rupestris strain, this latter hybrid probably would be entirely safe only on somewhat deep, weli-drained gravelly soils, including poor gravelly clays and loams. It is very hardy on such soils in my own locality and vines bear heavily on it. A mistake has been made in the Santa Clara valley undoubtedly in the use of unsound grafting wood and in planting it mostly on very compact soils, to which it is not adapted. The Champinis occur wild mostly on soils similar to those on which the wild Rupestris grow, but richer and in a driei region and on much drier ground. A vine growing wild on a rich soil, even if this is gravelly and mixed with small rocks, has a greater range of adaptation to moisture changes than a vine occur. ring on such soils which are almost devoid of humus and fine earth.

Aside from the hardiness of its roots the Lenoir has the ideal form of root-system for rich, heavy soils, which hold excessive moisture during spring and are apt to become dry later, in extending its main roots horizontally under the surface and its strong, penetrating laterals down vertically to a great depth.

The resistance-coefficient of Lenoir is 12 and that of Champini 14, which have not been found adequate under the climatic conditions of France. Which is the minimum resistance absolutely safe under California conditions is still an open question. It is known that Viniferas do not succumb as quickly here from the attacks of the Phylloxera as they do in France, which may be explained by the fact, that decay of the roots, which causes the death of the vines, does not proceed as rapidly in our soils during the summer, as it does in countries with summer rains.

At what degree of resistance a vine is immune from an injury to its roots by the Phylloxera in California, is a point which should command thorough investigation in the near future as a matter of the greatest importance. A stock with a somewhat low resistance but a good adaptation to existing soil conditions, is much safer than one with a high resistance against the Phylloxera, but without the adaptation. Our past experience has shown, that this latte: is as important (if not more so) as the Phylloxera question, in fact that the solution of one is valueless without the mastering of the other. The Lenoir and the Champini are the safest known at present for lands which cannot be properly irrigated and such soils as have been designated for them in this treatise. The former is probably the best for table grapes and other heary-bearing Viniferas on any kind of land excepting the very poorest. Anybody desiring to make plantings immediately should commence with these, but at the same time try some of the other hybrids of the four hardv species, and if some of them which have a higher resistance against Phylloxera are found to be equally as good in regard to adaptation to the existing soil conditions, these should be preferred for later planting. What relation the nature of a soil has to the hardiness of a vine can be seen most anywhere. In my own locality on a rich, deep, sandy or clayey loam the Cornichon is very hardy and 
the Tokay and Verdel are an easy prey to the disease, while on a gravelly clay of medium quality the first named succumbs easily and the other two vines are very hardy. In a somewhat rich, stiff clay on my own place the Verdel is hardier than the Tokay, while on a poor gravelly clay the latter is the hardiest. If there is so much difference between varieties of the same species, it can easily be seen, that a single resistant, that will do better than any other on any kind of soil or in any locality, will never be found. It will always be necessary to employ different ones to get best results, especially in mountain districts where soils vary so much.

Figure I as given below shows the range of adaptation of different species and of the two hybrids Lenor and Champini, ungrafted, in regard to moisture changes in the soil. Grafted to Viniferas it would become less, excepting Riparia, which probably. has a less drouth-resistant foliage than the Viniferas, as it occurs wild only in cool places in the shade of trees, but even this would become somewhat weakened after grafting on account of lack of sufficient affinity (similar to Rupestris) and the heavy bearing of the Vinifera-top.

FIG. I.

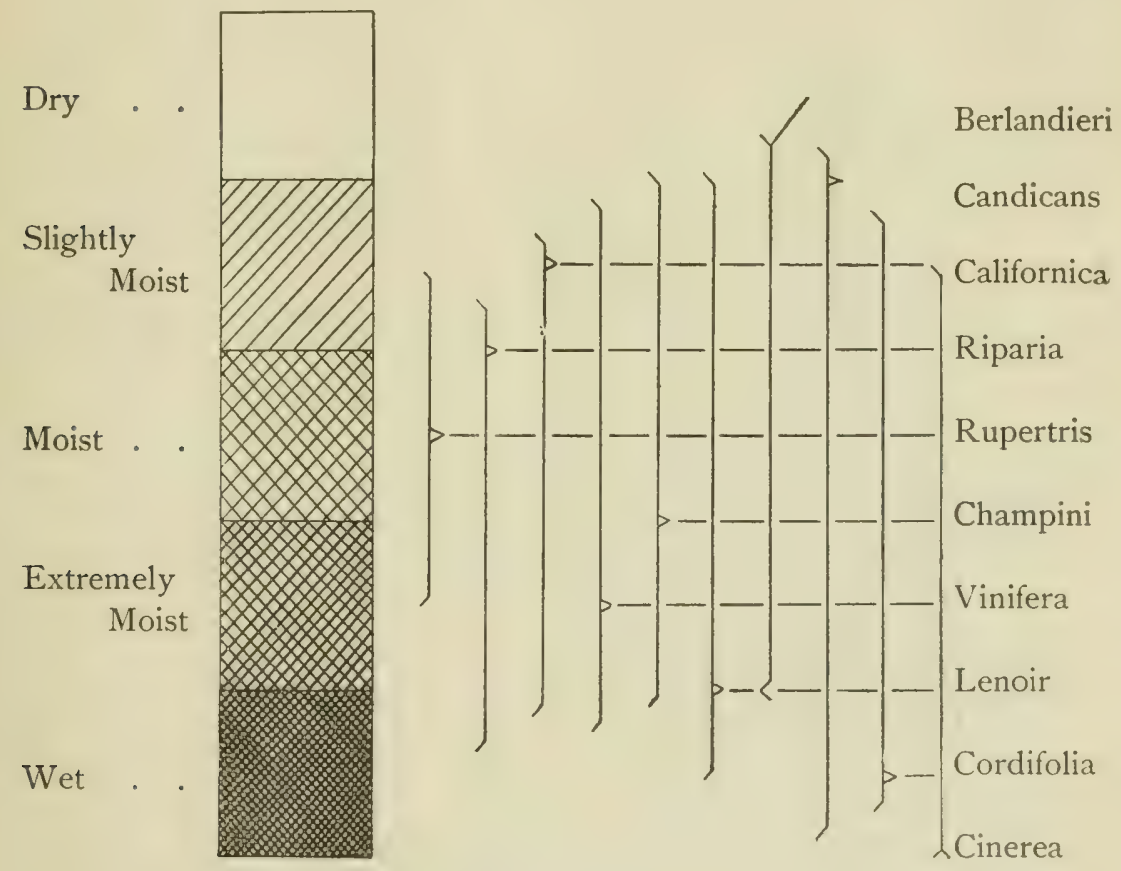

Of course the lines in the diagram show the range of adaptation only comparatively and approximately, as exactness would be difficult. Not only the inherent adaptability of the stocks will have to be considered, but also the form of root system, depth and nature 
of soil, etc. For instance in deep wet loams and clays or soils with groundwater a few feet below the surface a Vinifera may do very well, but a Champini sending down its vertical main roots into very wet soil or water would not succeed. A hybrid having a great drouth-enduring capacity but shallow roots would fail in a deep coarse gravel, where a Champini may prove successful. Even a Rupestris St. George may do as well as a Vinifera in such soil, as it has the advantage over the latter in its deep vertical roots, aithough less range of adaptation. But it is always safest, if a stock is chosen, which has adaptation to spare for a certain soil, than if it is deficient or doubtful. It can also be seen from the diagram that an improvement is possible on our two best known grafting stocks, the Lenoir and the Champini. By hybridizing a Cinerea or Cordifolia with a Candicans or Berlandieri and the progeny again with a Vinifera or Californica, a hybrid may result having a greater range of adaptation than the best we have at present.

FIG. 2

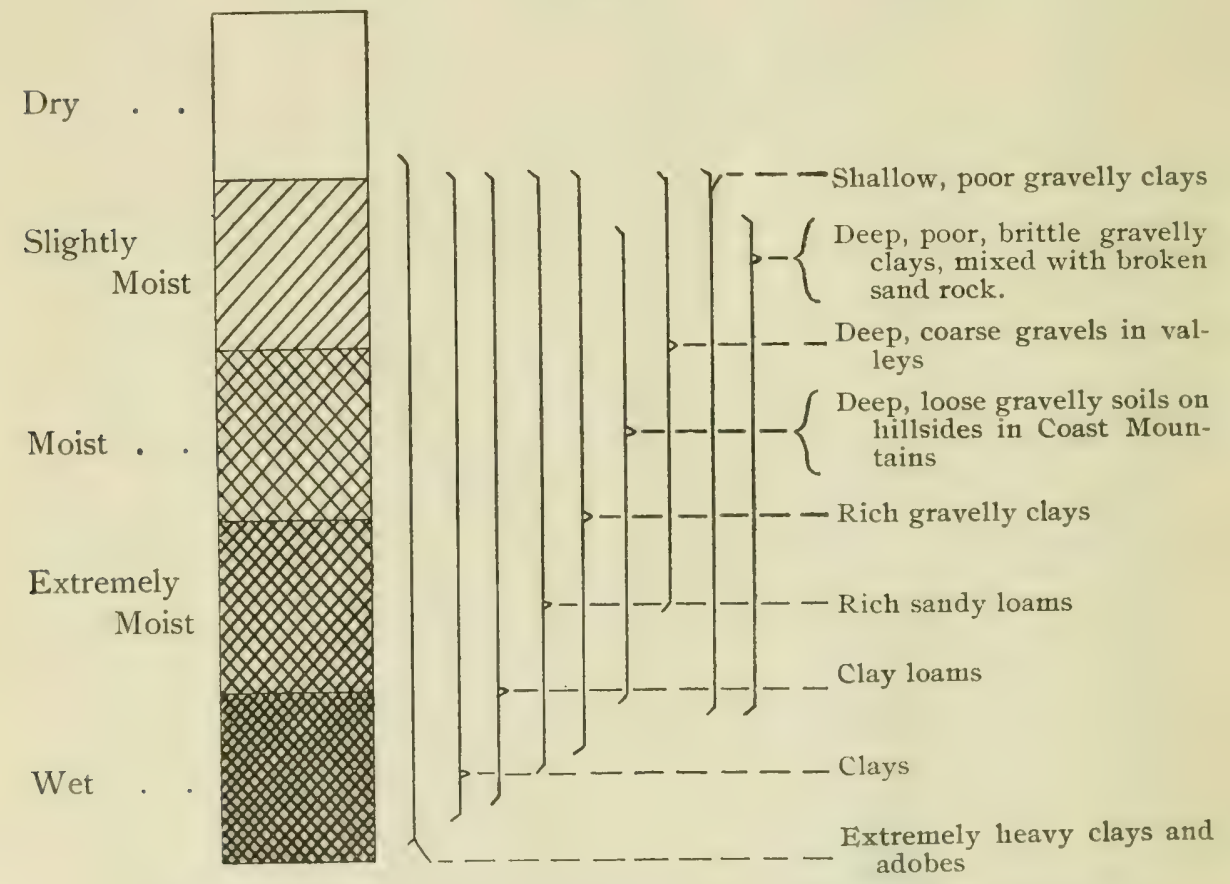

Fig. II shows the changes from wet to dry as they occur in the different soils of vineyards in the coast regions of northern Cilifornia, or may occur, if land is not carefully cultivated or rainfall is insufficient or vines have excessive foliage. This also is given only approximately and comparatively, as there are a thousand different combinations in the physical structure of our varied soils, according to depth, admixture of humus, clay or other binding material, broken sandrock, clayrock or granite, gravel or sand, etc., 
which all have a greater or less influence on their capacity of holding moisture in the spring and of retaining it through the summer. The more compact a soil is or if it is gravelly, the more fine eart! or clay is mixed with the gravel, the greater are apt to be the moisture changes. In localities where the rainfall is scant, heavy clays and loams may not be very wet during spring, or may be so only within a few feet of the surface, while below this they are comparatively dry. The great value of a vine, extending its main roots horizontally under the surface, as the Lenoir does, is apparent for such soils. From what has been said on the condition of soils, on which wild species are found or on which cultivated varieties have proved successful, it can be deduced that adaptation is principally governed by the moisture changes occu-ring in the soil and conditioned by the physical structure of the iaiter, by climate and cultivation. For this reason, adaptation, as taught by French experts, has not realized for California, as woisture changes in soils of the same physical structure are much greater wit! us t!an they are in France.

As the planting of resistant direct bearers which undoubtedly wculd avoid the trouble altogether, has becn recommensled oy somc, I shall say, that there is no vine of American origin at present. which approaches in the least degree the pecr'ess qualities of the Viniferas. Even with twice the expense of growing these, which indeed is not necessary, they will pay much betier than any baring resistant. For this reason no effort shnild be spared to retain them in localities where the disease has ociurred $w^{i t h}$ greatest severity, but which was caused mainly througl: ignorance of its irue character.

\section{CHAPTER III.}

\section{Soils, Adapted to Grape Culture and Preparatory Work for Planting.}

There are a great variety of soils in California and most any of them, excepting rich bottom lands near the coast or other parts of too moist anri cold atmospheric conditions, or where groundwater is too near the surface, can be planted to the grape vine provided the pecilliar labits of the different varieties and grafting-strcks are turierstond and the proper ones chosen. In this respect a good many mistakes have been made in the past and some losses of money incurred. In particular it may be said that brittle gravell clays of a reddish or brownish color mixed with broken sandrock and situated on warm sloping hillsides, are the very best, as they produce the highest quality of wine and table grapes, which is the desideratum desired.

In regions near the coast shallow soils, on which the grapes ripen better and whose impoverishment and drying out can be pre$\mathrm{v}$ inted by plowing under plenty of green manure, which is generally abundant, are better than deep, rich ones. Lands bring cov red with small brush as manzanitas, dwarf-oaks and other shrubs, when in their wild state, is in such localities indicative of their aclaptation to grape culture. Where large trees are growing, the 
soil is gerutrally too rich and deep to be arailable for this purjose, at least the services of an expert would be required to avoid mistakes in the choice of varieties. In the more interior locations a deeper soil is necessary, to maintain the vine properly and produce a good quality of fruit. Clays generally produce a higher sugar and firmer grapes than rich sandy loams.

In the preparation of the soil for vine planting, California methods have in the past been so slack that great losses of money or, as in some cases, even bankruptcy have been the consequence, especially where vineyards were planted on steep hillsides of poor sravelly soil. I shall not repeat anything here, that has been said on tnis subject in the chapter on preventive nethods of the California vine rlisease, but shall only make a few completing renarks with reference to mountain regions. Where vineyards have been planted on hillsides, the neglect of properly securing the natural richness of the surface of virgin soils, in preventing its washing by winter rains or loss of organic matter through combustion by the summer's heat, will make itself felt with greatest severity, when these vineyards will have to be replanted on account of the destructive work of the Phylloxera. The only way such lands could have been remunerative would have been to plow or dig trenches about 3 feet deep and? wide horizontally along the slops and filling them up with humus earth from above. Vines planted in stich trenches would have produced from $\gamma$ to 10 tons $p$ ar acie, where they yield col'y 2 or 3 tons by the go-as-you-please method.

The grape vine is the most grateful cultivated plant we have. Treat it well and intelligently and it will pay you back abundantly. It is better to have 5 acres producing 35 tons of grapes, than 50 acres producing only 100 tons, especially when grapes are cheap. The five-acre vineyard would have paid enough profits to set out an acre or two more every year, as described above, while the fiftyacre one depleted your pocket book in the first place and kept you poor afterwards, all the income from it being required to pay Asiatic labor, as has been the case in a good many instances.

In reconstituting vineyards destroyed by the Phylloxera or from any other cause, on resistant stocks in places where the land has been under cultivation for 10,15 or more years, the work becomes much more difficult. It is best to work over all lands that. will wash or slide from winter rains by trenching as described, instead of tirning the whole of the ground over 20 inches or two feet The better portions should be commenced with and the poorer and steeper ones left for four or five years, to cover themselves with natural regetation, if this will grow: if not, some cultivated plants which are valuable for green manuring, should be sowed and assisted by cultivation. If leguminous plants will not succeed, any. thing that will grow is better than nothing.

As has been stated, when doing such work, if the surface soil is devoid of humus, do not forget to put plenty of organic matte:in the form of brush, dead prunings and vines, straw, stable and green manure into the trenches. The first named should be pui in the bottom and the last named about 18 inches below the sur. 
face; it is plain that fine earth should be well filled in around such material and also that this should not be excessive. There is no danger of souring the ground easily in a California vineyard, as similar work is done in European countries, where decay on account of summer rains goes on much quicker. A grapevine is not easily affected by decaying organic substances in the soil, at least not thc right kind of a grafting stock. Humus is most important as no soil is productive without it, however rich in mineral ingredients it may be. It is almost an impossibility in California to cause any material benefit to deep-rooting perennial plants, by simply plowing under organic manures, not considering the great loss through combustion by the sun's heat. The benefit derived is generally of a physical nature only, in that compact soils are made more mellow and coarse gravelly ones denser and closer, and so both kinds more retentive in holding moisture. Of course this is very important.

It might be claimed that such work does not pay in California on account of high wages paid for labor. But considering that we need not plant our vines three or four feet apart in order to get them to ripen their fruit uniformly, it will not cost as much as work conducted on such a plan in European countries. A little more recourse to old world methods, seasoned down with a touch of American ingenuity in the use of proper implements, will make grapeculture the most remunerative pursuit in the State.

The next best way to the above-described method would be to dig deep and wide holes and then put a good amount of stable manure, coarse or rotted, in their bottoms. This will enable the young vine to get a quick start and get its roots down deep, so it does not suffer from want of moisture and nourishment.

When it becomes necessary later, commercial mineral manures can be applied by plowing under. As a rule such manures are necessary in California only when the vines become old, provided the land is worked over before planting, as described, and plowed deeply afterwards, as according to Prof. Hilgard's investigations, our soils are generally very rich in such ingredients to a great depth, on account of absence of summer rains and so of leaching of their valuable portions.

Stable manures intended for vineyard use should be kept dry and piled up loosely under a shed, to prevent the formation and escape of carbonate of ammonia. Mixing with land plaster or humus earth, or sprinkling with diluted sulphuric acid, will assist in this. It should not be left undisturbed very long but worked over occasionally. If it dry-burns, which means the formation of nitric acid, which is very volatile, the loss is still greater. In the winter it is safest to haul it right on to the land, where it is intenderi to go.

\section{CHAPTER IV.}

\section{Choice of Varieties of Grapes.}

This has been one of the most difficult problems confronting the vine-grower in the past, and has led to numerous mistakes and 
losses of money. The difficulty was greatly augmented by the passing under wrong and several names of some of our best varieties, which would have come undoubtedly sooner to greater prominence, if this had not been the case. Also giving wines of poorgrade varieties fine-sounding names, in order to enhance their salableness, as is sometimes imagined, is a reprehensible practice, which can only do harm. Some 30 or 40 years ago, when grapeculture took the form of a more general occupation, a great mistake was made in presuming that the most famous wine-grape varieties of Europe would also make the best wines in most any locality of California. Although our climatic conditions are not so varied as those of European countries where grape-culture is practiced, the fact has made itself felt, that it requires different varieties for the different localities to produce best quality and largest quantity, not considering our manifold soil conditions. Our past experience in this line will be of incalculable benefit to us, as the rehabilitation of our vineyards on resistant stocks is somewhat more expensive, and mistakes made now will be felt with much greater severity than in former times. Without fear of contradiction, I shall say that the highest quality, combined with from fair to good quantity should be the most desired aim in viticultural pursuits. To gain this object is not a difficult task at present, as we have it in our hand with the proper selection of resistant grafting stocks, to make choice varieties like the Petite Sirah, Beclan, Cabernet, Sauvignon blanc and Red Veltliner bear much heavier crops than they do on their own roots.

As the planting of white-wine varieties has been neglected in late years and less localities are adapted to the production of firstclass white than of red wines, all lands well suited to them, should be used for this purpose. All poor gravelly or sandy soils of the coast mountain regions of northern California, excepting those in very close proximity of the coast or where for other reasons tou moist atmospheric conditions prevail, where the more-rot-resistant red varieties like Beclan, Cabernet, Tannat and Petite Sirah are preferable, are best for white grapes, especially the early kinds as Red Veltliner, Sauvignon blanc, Semillon, Johannisberg and Franken Reisling. In more interior points where the acid of most of these would be too low for a sound fermentation, other kinds are probably better. In such places even richer soils may be used for the planting of white varieties. All rich lands, especially in th: coast region, are best for the growing of red grapes. Some exceptions will be found to these rules and past experience where such is at hand, is the best guide in this respect.

Dry wine varieties with a high acid in their fruit like Alicante Bouschet, Gros Mansene and all Italian varieties, are best adapted to warm interior points, as also the Valdepenas, which in spite of a comparatively low acid has the exceptional quality of a perfect fermentation, while varieties with medium to low acid like the Beclan, Cabernet, Tannat and Petite Sirah are better for the cooler coast regions. Such latter vari- 
eties with proper blends may be turned into good wines even in the warmer localities, as also varieties with a high acid may be valuable in small quantities for blending purposes in the cooler regions.

High tartaric acid contents of a grape in the fermenting tank especially during hot weather, are conducive of a sound ferment. ation in checking the development of secondary, injurious ferments, but give a wine a harsh, rough taste if too much is present. First-class white wine should contain about .06 per cent and red wines about .05 per cent of tartaric acid, or rather, bitartrate of potash (cream of tartar) as which it occurs in wines. Free tartaric acid is generally not present, except where unripe grapes went into the fermenting tank; wines made thus have a very harsh flavor. A wine fermenting its sugar contents out is not proof that the fermentation has been conducted properly. Low-acid grapes like Pinot, Meunier, Franken Riesling and Grenache, although they may apparently go through fermentation all right, favor the developmen of injurious bacteria, as acetic, lactic and tartaric, which cause, commencing generally during the after-fermentation, a steady increase of the general acid contents of the wine and finally spoil it. If the fermentation took place during cold weather in a well-protected cellar of an even temperature, such a condition need not be feared so much as if it occurred during hot weather.

For this reason all best dry wines are made in cool countries of grapes with a comparatively low or medium acid, which leaves the wine with a smoother, pleasanter taste. In hot countries like Italy, grapes must contain a high acid, besides high contents of sugar, body and tannin, in order to give the wine a sound fermentation and good keeping qualities. Such obstacles have been overcome at the present day, at least to some extent, with modern methods of pasteurization and filtration. Thin wines are also very much subject to injury from secondary ferments; such wines should be pasteurized.

Red wines intended for export or eastern shipments should contain a higher percentage of tannin than would be palatable for immediate or home consumption. The superfluous tannin will precipitate through the shaking of the wine in the casks, while in transit, and at the same time keep it in good condition and improve it. While the wine remains in the cellar its development is accelerated by a moderate amount of tannin and retarded by an excess of it. The best tannin and color grape for California is the Tannat, with the Alicante Bouschet for second place. Other varieties like Cabernet, Petite Sirah, St. Macaine, Mondeuse and Valdepenas contain good contents of tannin, in most localities enough for their own safety.

The above remarks are not made to give any information concerning winemaking, but to assist in the selection of proper varieties for a particular locality and in regard to the purpose for which grapes are wanted. 


\section{White-Wine Varieties for the Coast Region of Northern California.}

Red Veltiner-Description: Vine very vigorous, with strong spreading canes. Leaves large, deeply five-lobed, dark green and rough above, lower side white woolly during forepart of summer. Bunch medium, somewhat loose, pyramidal, with from small to medium-sized pink-colored berries.

This variety has originally come from Austria, where it is esteemed, according to Babo and Mach, on account of the superiority of its wine and good bearing qualities. From there it has been brought into Germany, where it is grown to a small extent and hnown among common vineyardists as the large Traminer, because its grapes have the same pink color as those of the Traminer. For this reason it occurs in California also under both names: but the same color of the grapes of two varieties is no mark of relationship. nor is a different color a good mark of non-relationship. If the above (iescription is compared with that of the Traminer by Prof. Hilgar: in his report on winegrapes, the great difference between the two vines can easily be seen. The Traminer has no value for California, as it is a shy bearer and produces a wine of poor keeping qualities. Some Veltiner wine made in this locality (Santa Cruz Mountains) from grapes grown on a poor gravelly soil by inexperienced wine. makers and sold to an eastern dealer, has brought $: 30$ and $40 \mathrm{c}$ a gallon, when other wines did not bring one-half of that amount. A blend of two-fifths Veltliner, two-fifths Franken Riesling and one. fifth Johannisberg Riesling produces a wine of first-class quality. This grape has a great value for the coast region, as it resists rot better than any other early white-wine grape with long horizontal canes, and bears heavily on all gravelly soils. In more interior places it probably needs an addition of some other more acid variety, like the Sauvignon blanc, in order to produce a wine of good keeping qualities.

Sauvignon blanc. This is a somewhat shy bearer on its own roots, but does better on resistants. It is confounded in this locality a good deal with the Muscadelle du Bordelais, which it resembles very much in the appearance of the vine as well as the fruit. But while the Muscadelle generally drops its fruit by coulure two seasons out of three, the Sauvignon blanc very selem does, where it stands on a soil of medium or good quality. This grape probably has a greater general adaptation than any other Vinifera varietr. as it holds its acid well even in hot interior vallers. Its wine in itself is somewhat rough, but is very valuable as a blend with wines of less quality and lower acid and sugar. The vine is about as nearly frost-pronf as any variety can be, as it starts its growth rery late in the spring. It requires long horizontal canes to bear well.

Semillon. This has been the favorite white-wine variety in California and is therefore so well known, that it is not necessary to mention any of its characteristics. It is extremely liable to get damaged by late spring frosts, as it starts its growth very early. Its behavior on resistants, at least Riparia and Rupestris, is far from? 
being satisfactory, but it may do better on some hardy ViniferaAmerican hybrid.

Riesling Johannisberg. This is rather a shy bearer, and easily fiosted in the spring. On a poor gravelly soil in the Santa Cruz. mountains it bears fairly well and makes a wine of fine quality. This as well as any other Vinifera variety will undoubtedly do much better on some hardy resistant than on Riparia or Rupestris or even its own roots.

Sylvaner or Franken Riesling. This is an immense bearer in this locality, if pruned with long horizontal canes, but should be planted only on dry gravelly soils, as its grapes are much subject to rot. Its wine by itself is not best quality, but a good wine can be made of it, by blending in the fermenting tank with the Johannisberg Riseling or Sauvignon blanc and in some places even with the Red Veltliner. It starts growth late in the spring and is seldom hurt by frost.

Pinot Chardonay, from which the celebrated Chablis wines are made in France. There are only a few vines of this variety planter here, but which give promise of its value as a good bearer.

Sauvignon vert. This is similar to the Franken Riseling, an immense bearer, and its fruitfulness is not impaired by frost, as it bears on canes from adventitious shoots, if its first growth is cut down. It should also be planted on dry gravelly soils only, as on rich ground it has not sufficient sugar and makes then a thin insipid wine. For some more interior places, like Napa county, a sreater value is claimed for it. It does well on resistants.

Green Hungarian. On dry gravelly soils with warm exposure this makes a good, light, neutral wine, but does not ripen early enough to be adapted to many coast locations. Different from the other varieties mentioned, it can be stool-pruned and somewhat short. It bears heavily.

\section{Red Wine Grapes.}

Petite Sirah. This and the Serine resemble one another somewhat, but have undoubtedly originated from two different seedlings, as the difference between the two varieties is too great to be explainable any other way. The leaf of the Petite Sirah is somewhat more deeply lobed and of a deeper green color than that of the Serine. The first-named starts its growth later in the spring and its leaves hang on later in the fall. It has also a larger bunch and sets fruit much more profusely.

As the Petite Sirah occurs here, there is another variety mixed with it, which has a small, generally loose bunch and large leaves, covered with a heavy, cottony down on the lower surface. This variety is worthless. The Petite Sirah is a most valuable grape, as it bears heavily and produces one of the best red wines in the state. It does exceedingly well on all kinds of resistants. I have been told lately that it is the same grape, that was known in former years as Pfeffer's Cabernet. 
Beclan. This is probably the best grape for rich land, whether sandy or clayey, in the coast region. It grows, bears and ripens its fruit early, similarly to the foregoing. It also does well on resistants and makes a fine wine, which has great value as a blend with Cabernet.

Cabernet Sauvignon. This is a shy bearer on its own roots, but does better on resistants. It is the most rot-resistant grape we have and is therefore valuable in places with moist atmospheric conditions. It requires long horizontal canes to bear well.

Tannat. This is also very resistant against rot and an immense bearer. Its value as a tannin and color grape has been stated. There are two varieties of it as it occurs here, which are called in France T. male and T. femelle. The leaf of one is not quite so deeply lobed as that of the other and its bunch not quite as large, but closer; it is the better bearer of the two, but also more subject to the California vine disease. It does poorly on Rupestris St. George (the same as all other varieties on this stock) but bears immensely on Riparia.

Alicante Bouschet. This occurs a good deal under the name of Petit Bouschet, which is giving a bad name to a good grape, as the latter is a much inferior variety. The former can be easily distinguished from the latter by its leaves, which are shiny on the upper side, with the edges turned back. The Petit Bouschet has flat and more downy leaves. The Alicante Bouschet is an immense bearer, but it is reported from France as not doing well on resistants, but will probably behave more satisfactorily on some hardy Vinifera-American hybrid.

Carignan. This is so well known, that it is not necessary to mention its good qualities. It ripens later than the other red varieties mentioned and does best on clays. It behaves well on resistants.

Mondeuse. This makes a good wine and bears well in some places, but in others its behavior is not so good in either respect. It does not seem to do well on pure American stocks. The Mondeuse and the Carignan are the two best of the ordinary varieties.

Valdepenas. This is best adapted to warm interior localities. It has the reputation of fermenting high sugar contents out without any trouble and makes a very superior wine.

\section{Table Grapes.}

Flame Tokay. This is the most prominent table variety, as it: bears heavily and its fruit brings the highest price in the markets, provided it is of good quality. To produce such is sometimes difficult, as not all soils and locations will do this. It requires for its perfect development a somewhat dry atmosphere; where this is heavy and moist from ocean winds, it is not of a marketable character. In regard to soil it is best on a poor gravelly clay of a reddish or brown color; if the soil is rich, it should not be deep.

If the vine is planted on rich ground, where it does not ripen its fruit well, it should be trained to a high, large, spreading head 
and pruned with a great number of canes of two and three buds. Its young growing shoots will be shorter and more upright then. its bunches smaller and looser and in consequence its berries more evenly ripened and better colored. On very poor soils it should be trained to a lower and closer head with fewer fruit canes.

Verdel. This produces its best product on a gravelly clay of medium quality. On such a soil its fruit keeps longer and better than that of any other variety. In the Santa Cruz mountains it is generally one of the best paying varieties grown, as it bears immense and regular crops. Where the ground is too rich for a perfect product, the quality and sugar contents of this can be improved by a similar mode of pruning as that recommended for the Tokay, but not quite so many canes need be left. It should only be planted in places well protected from the north winds, as its young canes in the spring break off very easily and its fruit is also damaged quite often if vines are standing in an unprotected place.

Cornichon. This is the best table grape variety for rich ground, especially a sandy loam. It is trained and pruned in all kinds of manners, from a somewhat low and close head with few half-long canes for poor ground to a high spreading head with numerous short canes of three buds for very rich ground. For soils of medium quality the best way of pruning is intermediate between the two extremes described. It is a favorite grape for attack from small birds, which bore holes into the ends of the berries and sometimes cause ruin to a whole field. The shotgun remedy is the best means of protection, as the birds generally are intelligent enough to learn that it is best to stay away.

Emperor. This is a very fine, although thick-skinned grape. of good marketable and keeping qualities. It requires also a soil of good or medium quality with warm exposure, and is pruned similar to the foregoing. No first-class table grapes can be grown by any other system than head pruning. Excessive vigor of a vine can bi overcome with a high spreading head and more fruit spurs, as well as with pruning by the Guyot system or extension to one side.

Muscat of Alexandria. This is coming into disfavor somewhat in the coast region on account of its susceptibility to the California vine discase and the easy rotting of its fruit, if caught by the early fall rains. It should be planted only on such soils where it will ripen its fruit early. Its liableness to coulure can be corrected by pruning to three buds, canes extending upwards at an angle of about 30 or 40 degrees, with a close head and few fruit canes, if on poor ground and by careful suckering several times before the bloom. The Muscat is a very sensitive vine; too much or too little vigor, too much moisture in the ground or too little, as also a strong north wind may cause coulure.

\section{CHAPTER T.}

\section{Pruning, Grafting and Budding.}

1. Pruning. There are numerous systems of pruning practiced 
wherever the grape rine is grown. In general it may be said. that the pruning must conform to the variety of grape, to the vigor and size of the vine. to climatic and atmospheric conditions of the locality and to the lemands of the market for the fruit. There are some minor consiclerations, but I believe these are the principal ones.

The quantity and quality of the crop is very much influencer? by the nature of the soil. On account of this a vine may have too much or too little vigor. to bear properly. To maintain the proper equilibrium between crop and woodgrowth. should be one of the objects of pruning. The rigor of a vine can be lessened with higher training. more spreading head and more numerous or longer fruit canes. It can be increased by reversed methods from the above. It is always best, especially on virgin soil, to start with a lower heari than appears necessary at the time for the production of greatest quantity and best quality. A vine can be much more easily raiseci up higher with short upright spurs. than lowered if it has been raised up too high in the first place. In general. not enough differ ence is made in the winter pruning of large vines and small ones. as also in their training to a higher or lower head according to the richness of the ground. Training a rine to a high and spreading head on a poor soil, takes all its resources to nourish this, without it being able to bear. On the other hand, where a vine has been trained to a low head on rich ground, the woodgrowth is so immense, that it robs the sap. which should properly go into fruit. This is more pronounced with some rarieties than with nthers. Th: same may be said of the manner, heads of vines are spread, more or less. It is much better for the health and longevity of a rine. if it has a little too much vigor and less fruit, than the reverse.

Excessive moisture as well as extreme dryness during the time of derelopment and ripening of the fruit may postpone its maturing or cause inferiority of the same. The first generally does not occur in California, except during the forepart of the season. when it does its harm in causing nnnecessary woodgrowth, injurirus to the proper cievelopment of the fruit and the healthinlnes: of the vine. For this reason, vines on poor gravelly hillsides in mountain districts, where they do not grow excessively on accoun: of the poorness of the soil and in consequence later on do not suffer for want of moisture, produce the firmest. sweetest and a good many times the largest berries. Where vines are growing on rich ground, heavily charged with moisture during spring, their an-

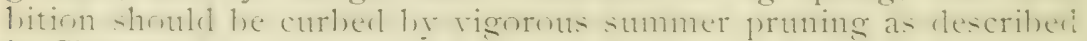
in Chapter II.

Too much old wood may prevent a rine from doing its best. The arms of a vine should be renewed occasionally. The smaller ones may be cut near the main body, but the large ones should not be cut nearer than six inches from the trunk and should always have one or two canes of young growth at their extremity. Large cut surfaces should be painted over.

Excessive crops may retard the maturing and the formation of the necessary sugar contents of the fruit. Large trees standing 
near vines, robbing the ground of moisture, when the latter are in great need of it, also prevents proper development of the sugar contents of the fruit. The sugar is highest, if vines on rich ground are trained to a high spreading head and pruned with numerous short fruit spurs and on poor ground to a low and close head with few canes. On intermediate soils the pruning and training should be between the two extremes.

Head or stool pruning is best adapted to California conditions, as the ground can be more carefully worked and its moisture contents better regulated. Varieties like Petite Sirah, Alicante Bouschet, Beclan and others will bear just as well and more regurlarly by hearl-training and pruning to 4 or 5 buds, or even less in some places, than by leaving long horizontal canes. It is best to put varieties like Riesling, Cabernet, Sauvignon blanc, Semillan, etc., which do not bear except with very long canes, horizontally placed, on gravelly, loose soils, which are not so subject to drying out and can be more easily worked; or they may be put on steep hillsides, which can be conveniently worked only in one direction. If the soil is very poor, it is best to train any of the varieties mentioned to a very low head, leave only one long cane and bend it around in a bow, the tip end almost touching the ground, or this can be run into the ground 5 or 6 inches and the bow above tied to $?$ picket. This also gives the vine more stability against strong winds.

2. Grafting. According to the size of the stocks there are two principal methods of grafting, the common cleft graft and the English cleft or tongue graft. Instead of the former, if stocks are of sufficient size, the saw-in method, as I generally call it, may be practiced. This mode of grafting is done by cutting across the edge of the stump with a California pruning saw. The cut is trimmed out on the sides with a sharp pruning or budding knife. A shoemaker's leather knife, which has a narrow, thin blade and is made of good materianl, is very handy for this purpose. The scion is shaped by first cutting it in wedge form as in the common cleft graft, and then making another slanting cut opposite the bud, from the node down to the point, which should have about the thickness of the width in the cut of the stock at its lower end. The two edges on the cut of the scion are shaved down a little, so they do not hinder in making a close fit. The scion is then inserted and driven down with a small wooden mallet. It requires a good deal of practice to make this graft properly, but if this is acquired, it is quickly and effectively done. The wood of the scion should press snugly in its full length against the wood of the stock, in order to enable the former to draw sap immediately. The inside of the bark of the scion should fit against the inside of the bark of the stock in order to make proper connection through the callousing of scion and stock.

This graft has the advantage over the common cleft graft in that the stock can be cut off just above a node, at which a connection is made much more easily than at an internode. If the bud on the stock is in a smooth place, it can be cut out with the saw, and 
the scion inserted in such a place generally grows without failure. The slanting cuts on the scion should come up to the bud as near as possible, so this rests closely against the stock. This graft can be employed on stocks not much more than one-half inch in diameter. Such small stocks would of course need a ligature. In tying grafts interspaces should be left between the windings, to leava room for the callous.

On dry gravelly soils most anything will do for tying material, but on wet heavy land bluestoned raffia is the best, in order to prerent rotting of ligature and also decay of the cut surfaces of both scion and stock. Raffia is bluestoned by soaking it in a three per cent solution of bluestone ( 4 ounces in a gallon of water) for 24 hours; it is then hung up to dry. Before using it is washed thoroughly in running water, to remove the bluestone from its outside, and is then kept moist and ready for use.

With the suckering of the grafts one should be very careful. It is best not to disturb the grafts with the appearance of the first suckers, but simply pinch these. After a while the earth may be removed from around the grafts and all the suckers cut off, provided the scion has made a growth of one foot or more. If this is not the case two or three suckers near the top of the stock should be left and pinched again. Too severe suckering will easily kill the graft or even the vine, as it is apt to cause souring of the sap.

Along in July or August all the grafts should be carefully examined, the tyings and the roots, that have started from the scions cut off, and then well mounded up again, as the knitting of the scion and the stock goes on better under ground than above.

Cuttings to be used as scions are best kept in boxes filled with sand and placed in a cool place. The sand can be moist when the cuttings are first put into it, but gradually as the sand dries out the cuttings become "cured" and are then much less subject to drying out, if used in the field and the ground should become very dry, and also less subject to decay, if the ground should be very wet. Cuttings to be used for propagation on their own roots are better buried outside in a well drained place of gravelly or sandy soil.

3. Budding. This has not been given a fair and thorough trial in California so far and it is therefore difficult to say at present, what can be done in this line. As our atmosphere is much drier during the summer than that of France. it probably will need som: modifications. How to select buds for budding and how to insert them, has been well described by Prof. Twight in one of the State University bulletins, which is sent to any one who asks for it.

\section{CHAPTER VI.}

\section{Creation of New Hybrids for Grafting Stocks.}

As has been stated, grafting-stocks of a much greater adaptability to different soil and climatic conditions than the pure species possess, can be obtained by crossing or hybridizing varieties belonging to different species. Crossing and hybridizing do not mean exactly the same thing. A hybrid is obtained from a seed. 
the ovule of which had been fecundated by the pollen of a variety belonging to a different species, while both parent varieties of a cross are of the same species. More vigorous and hardier types are produced by hybridizing than by crossing; for this reason it is of greater value in the creation of new grafting-stocks.

To make the operation better understood it is necessary first to give a short description of the flowers of different seedlings and the process of fecundation. There are three kinds of flowers in grapes:
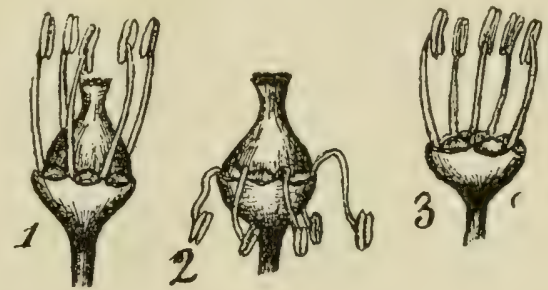

1. The perfect, hermaphrodite, with well developed pistil and stamens, capable of self-pollenation, Fig. 1. All Viniferas which are cultivated have such flowers.

2. The practically pistillate flower with perfect pistil, but weak recurved stamens, generally incapable of self-pollenation. Fig. 2.

3. The staminate flower, with perfect stamens, but without pistil. Fig. 3. Example: Rupestris St. George.

Only vines with either hermaphrodite or pistillate flowers, pos . sessing a perfectly developed pistil, can bear fruit. But in most cases the pistil does not develop into a grape, unless one or more of its ovules have been fecundated by a pollen grain.

\section{Pollenation by Nature's Method.}

The pistil of a hermaphrodite flower may be pollenated by the pollen of its own anthers, the enlarged upper portion of the stamens, but with pistillate flowers generally only cross-pollenation is efficacious, that is, the pollen must come from a different vine. This latter is also with hermaphrodite flowers more effective and consequential of better results. It seems to be Nature's preferred method in producing new and more vigorous and valuable types in plant life. Gentle winds and small winged insects, visiting the flowers to gather nectar, are pollen distributors. Whenever a pollen grain is deposited on the stigma, the enlarged upper portion of the pistil, and this is in its receptive state, which is generally after a flower has opened on a warm fair day at about $10 \mathrm{a}$. m., it begins to germinate in the moist, gummy substance and send down its threadlike roots in one of the minute tubes of the pistil, penetrating the ovule cell-wall and intermingling its substance-protoplasmwith the protoplasm of the ovule. The pistil holding such a fructified ovule at once begins to enlarge and in time becomes a mature grape and the ovules develop seeds within.

As male vines have not a flower with pistil, it is clear, that 
they cannot bear, but they are certainly of value or Nature would not have developed them. Nature's tendency in its creative designs for the reproduction of improved forms is apparent and so it makes cross-pollenation imperative. Generally the most vigorous and enduring offspring is produced by crossing vines with pistillate or hermaphrodite flowers with some which have stamiate flowers.

\section{How to Hybridize if Parent Vines Bloom at the Same Time.}

This is easiest, if the mother vine has weak recurved stamens. The selected mother vine should be in the best of condition, receive good care and be irrigated several times during the latter part of the summer. As soon as the flower clusters appear and if there are very many of them, some should be cut off, so the vine is not overburdened. The vine should be noticed daily, until some of the buds on the flower-clusters begin to open. These should be clipped off then and each cluster, which is to be operated on, enclosed in a small sack of tissue paper or close-meshed gauze, so insects canno: enter. The next day at about $10 \mathrm{a} . \mathrm{m}$., if the weather is warm and fair, visit the vine and if some flowers on the enclosed clusters have opened, brush over these several times with a newly opened flowercluster, taken from the vine which is intended as male parent, knocking off flower-caps and spilling pollen profusely all over the cluster. If clusters used for pollenating are plenty, enclose one of them in the sack, letting it rest on the cluster to be pollenated untii the next day, when with fresh clusters the operation is repeated. Every day the vine must be visited, the newly opened flowers pollenated until all the flowers have been operated on. If the clusters are very large and close, some of the flowers should be cut out, so the young grapes are not overcrowded. All the seeds borne by the sacked clusters will be crossed or hybridized by the variety used as male parent.

If this latter vine is growing right next to the vine with reflexed stamens, all that is necessary is to train two arms, one of each vine, along each other, and then enclose them with a light sheet of cloth to keep ont insects. Daily shake the arm of the pollenating vine, which should be trained above the other, so pollen is spilled all over the flower-clusters of the pistillate vine.

If the mother vine is a variety with hermaphrodite flowers, the operation becomes more difficult. In this case at commencement of flowering time all the open flowers of the cluster to be operated on, are clipped off and then all caps just about ready to shed, are detached with the point of a needle or pin, the anthers all hooked off with a tiny hook, made by bending the point of a pin back at an acute angle. The flowers thus prepared are then pollenated as previously described. Great care should be taken to prevent pollenation of the flowers by the pollen of their own anthers. For this reason the vine must be visited every day at 9 or $10 \mathrm{a} . \mathrm{m}$., and the cperation repeated as described. If any flowers are found opened. it is best to clip them off, as it is also ivell to thin out some of the bucls on very large or close clusters. This facilitates the work and causes the remaining ones to set with greater certainty. 


\section{How to Hybridize Vines Not Blooming at Same Time.}

If the two vines to be crossed do not bloom at the same time, then either the blooming of the earlier one must be retarded by cutting off the first shoots in the spring or by pruning very late, and the later one be made to bloom earlier by pruning very early in the fall, or by saving pollen from the earlier to apply to the stigma of the later.

\section{How to Gather and Preserve Pollen.}

At blooming time, as soon as most of the flowers have opened, gather a supply of flowering clusters and carry them to a light room without shaking or jarring. A new clean tin box about :3 inches square and one inch (leep is a good receptacle to preserve pollen in. Take the gathered clusters by the stem and strike them gently into the open box several times. Then clip off the open flowers into the box, put the lid on and shake the box well, so all the pollen becomes dsilodged from the anthers. Take the lid off again and leave the box stand on window sill for 20 or 30 minutes. Put the lid back and shake once more, when on opening most of the pollen will be seen sticking to the bottom, sides and top of the box. Winnow off all the anthers. corollas and other particles, which may have falleni into the box. Place the box open now on window sill for one or two hours, when the pollen will be dry and in good keeping condition. Put on the cover again and paste over the seam a strip of paper, to keep out air and small insects.

\section{How to Apply Preserved Pollen.}

When the flowers, to be operated on, have opened, properly prepare them as described and then apply the pollen with a small camel's hair or cat's tail hair pencil, moistened in pure water, to the stigmas. Carefully sack the clusters after the operation, so insect. cannot carry in pollen from other vines.

\section{How to Keep the Seeds.}

As soon as the grapes on the pollenated clusters are fairly ripe, they should be gathered, the seeds taken from them and dried in a ventilated room. They should then be carefully wrapped and kept in a cool, dry place.

In the above I have followed principally the directions, as given by Mr. T. V. Munson of Denison, Texas, the noted originator of numerous crosses and hybrids in one of the bulletins of the Texas State Experiment Station.

\section{Mr. Burbank's Method.}

According to a writer in "The Pacific Tree and Vine," Mr. Luther Burbank proceeds in the following manner in creating his wonderful fruits and flowers:

"A supply of the fructifying pollen anthers is carefully gathered from the desired plant parent, usually the day before it is to bc used, and carefully dried. When the proper degree of dryness has been obtained, the pollen powder is secured by carefully shaking 
the anthers over a watch crystal, until its surface is dusted with pollen. The blooms of the seed parent, that is to receive the pollen, have been previously prepared by removing about nine-tenths of the bloom buds, when they began to show the petal color. This is (lone for convenience in operating and to avoid overcrowding the tree's capacity. Before the petals open, each of these buds is carefully cut into with a small sharp knifeblade in such a way that the petals, a part of the sepals and all the attached anthers are removed as the knife makes its circuit, leaving the pistils exposed but uninjured by the operation. The removal of the corolla balks the bees and other honey-sucking insects, that are pollen distributors. Mr. liurbank chooses for pollenation the time when the first hum of the hees is heard in the trees, as this seems to be Nature's indicator, and he finds all conditions then most favorable, and believes the pistil is then in its most receptive state. His instrument for pollenation is his finger tip, applied first to the dusted surface of the crystal until enough pollen adheres, then quickly touched to the pistils of the prepared blossoms one after another. These welcome the pollen and the fructifying agency begins at once its journey to the ovule. No matter what comes now , the opportunity for outside pollen has passed.

The seeds resulting from cross-pollenation are of course gathered with great care, seedlings are grown and the closest watch is kept upon characteristics and habits from germination onward. The little seedling may disclose its combined parentage, or it may give sign that it has drawn up something from the profound depths of the converging streams of remote ancestry long before reaching the blossoming or fruiting stage. These crossbred plants are again crossbred, as the purpose of their master indicates, for he always works to a definite purpose. And thus the wonderful processes go on year after year. Sometimes thousands of specimens have to be destroyed, yielding no results."

\section{Planting the Seed.}

The seed should be prepared about a week before sowing, by soaking in hot, but not boiling water for about 2 hours, when the cold water is poured off and another application of hot water given it for 2 hours more. Then drain the water off and wrap the seed up in a piece of course cloth and lay it in the sun during the day, moistening the cloth, whenever it becomes dry. In the evening take it into a warm room and leave it there during the night. The latter part of February is a good time to sow the seed and it generally takes from two to three weeks before it germinates.

\section{The Seed-Bed.}

Select for the seed-bed a piece of warm rich sandy soil, which must be worked over deeply with plow or spade and then made smooth with the rake. Sow in drills about three feet apart and about one and a half inches deep. Cover with fine mellow soil and smooth over again with rake. The seed-bed must be carefully 
watched and kept clean from weeds by frequent hoeing and irrigated several times during the summer.

\section{Testing the Seedlings for Resistance Against the Phylloxera.}

In order not to waste time with vines, not resistant against the Phylloxera, especially if a vine has been used as one of the parents, which had only a slight resistance or none at all, pieces of roots from a Vinifera variety covered with the insects should be buried alongside the seedlings in June. Care should be taken, while doing this, not to expose the insects to the sun or drying winds as this might kill them. A moist sack wrapped around the roots, while moving them, will prevent this.

The seedlings should be watched closely, their roots examined at least once a month during the summer and if the Phylloxera is found feeding on them to any extent, the vines should be pulled up as soon as noticed. The insect will always attack those plants first. which have the least resistance in the lot. So if the seed-bed con tains vines, having a resistant-coefficient of $4,6,8,10$ and 12 , it will be found principally on the seedlings having a resistance of 4 , and very few on any other. As soon as these are destroyed, it will attack the plants, having a resistance of 6 , and so on. Before this habit of the insect was known, numerous mistakes were made in France, in supposing low-resistant vines immune, which did not prove so at all as soon as they were planted by themselves in a field. A Lenoir, for instance, is not attacked at all as long as Californicas or Viniferas are near, and a Californica appears perfectly immune, if healthy Viniferas are growing near it. For this reason it is best to leave the young vines in the same place for another year and continue the experiment in examining the roots carefully every month during the summer and pulling up everything that seems good feed for the insect. Along in September of the second year the roots of the remaining seedlings should be carefully examined to see what effect, if any, the attacks of the Phylloxera had on them, as no vine is entirely free from its presence, however high its resistance.

At the end of the second year the young hybrids may be taken up and then each one of them planted by itself a considerable distance from any other low-resistant vines. A good plan to follow is to plant about one foot from every one of them a Rupestris St. George (16) or a Champini (14) and then bury some phylloxerated roots near them. If on examination during summer and fall the Phylloxera has shown a preference for the roots of the seedlings, it is plain, that their resistance is not as high as that of the accompanying vines. If, on the other hand, the insect has preferred the roots of the two vines mentioned, it is proof that the resistance of the young hybrids is higher than that of the Champini or Rupestris St. George.

On examining the roots of the vines during August, if swellings on the small rootlets to any extent or still worse, if any at all on the larger roots are observed, the seedlings should be rejected. According to Prof. Millardet's (of France) resistance scale, if 40 nodosities 
(swellings on the small rootlets) on 100 rootlets are present, the resistance-coefficient of the vine is 16 , the minimum one which is considered safe in France in most soils. If more are to be seen, the resistance is lower, and if less, higher. If any swellings occur on the larger roots (tuberosities), the resistance is below 15, and then safe only in exceptional cases. The larger the nodosities and tuber. osities are, the more quickly the roots will rot and the lower is the resistance of the vine.

The next step to be taken is to ascertain whether the seedlings, which have shown sufficient resistance against the Phylloxera, wil; root readily from cuttings and graft well to Viniferas. In regard to the latter quality, there will not be any trouble, if the species previously mentioned, are used for hybridization, as they all possess this. In selecting parents for hybridizing purposes in general, it is necessary that the several qualities desired in their progeny, are the aggregate qualities of the former. No hybrids will have any value in California, which have not one of the four hardy species, Candicans, Berlandieri, Cordifolia and Cinarea, as one of their parents. In regard to the resistance of a new hybrid to the California vine disease or its adaptation to California soil conditions, the general aspect of foliage and root systems, whether it takes more after one parent or the other, is indicative of its strength in this respect, but it must be remembered that the greatest range of adaptation is obtained by hybridizing a vine adapted to wet conditions with one adapted to the very driest. Numerous hybrids will have to be rejected even in this respect before something is obtained, possessing the greatest usefulness. Wonderful achievements are possible in this line, if properly and intelligently followed up, and it may also not be out of reach, to produce vines entirely equal to the best Viniferas in regard to quantity and quality of the fruit, but with a much more drouth-resistant foliage. 

